\title{
Study on Assessment of the Relationship between Success and Job Satisfaction for Social Service Workers in Penitentiary Institutions in Albania
}

\author{
Enida Kume
}

“Alexander Moisiu” University, Durrës, Albania; enidak@hotmail.it

\author{
Doi:10.5901/ajis.2016.v5n1p231
}

\begin{abstract}
This study aims to analyze job satisfaction and the factors affecting the overall success of Social Service Employees of Penitentiary Institutions in Albania. Among 25 satisfaction items the Factorial Analyze identified five factors as latent variables: satisfaction from pay and benefits, working environment, management, peers and superior. These factors have a positive relationship with Social Service Workers success. Together they explain about $60 \%$ of the total variance of success in the work of social service employees. The main important factors of this analysis were pay and benefits, followed by peers and management. In contrast, working environment and relation with superiors have less impact on their success at work.
\end{abstract}

Keywords: Job satisfaction, success, social service workers, penitentiary institution

\section{Introduction}

Albania has 23 penitentiary institutions in which people of different ages, gender, and educational, social and economic level, suffer criminal sanctions. These institutions offer social services for their inmates. These services are performed by social service specialists. It is relatively new. According to the current legal framework, this sector is the main one for the employment of social service specialists. The results of a previous study (Kume. E. 2013) have shown that this sector is considered by social service employees as a good opportunity to exercise their profession and as a job that is in line with their expectations. Given the target groups (prisoners) to whom this service is offered, it is naturally that "...social service workers must often deal with intense emotional issues and are frequently confronted with disturbing situations (Cranny, C.J. et al. 1992; Lund, D.B. 2003; Zaimi, et al. 2013). Therefore the assessment of job satisfaction level and the identification of influencing factors are very important in order to plan and carry out the necessary intervention in order to better implement this service.

Job satisfaction has been defined as an emotional reaction to the work situation (Ilham, 2009, Locke, 1969, 1976). The best definition for job satisfaction is the one given by Locke: "job satisfaction is a pleasurable or positive emotional state resulting from an appraisal of one's job or job experiences" (Locke, 1976). On the other hand, if we refer to Ilham (2009): "employee satisfaction refers to the positive or negative aspects of employee's attitude toward their jobs or some of its characteristics"

Bernal, J.G.,et al. (2000) point out that job satisfaction is affected by employees' perceptions of their job and the organization for which they work. According to Homburg and Stock (2004) employee satisfaction is "an attitude that results from an evaluative process, where some comparison standard about the work environment is performed with the actually perceived work environment".

The purpose of this study is to evaluate the effects of job satisfaction in the success of the work of social employees of penitentiary institutions in Albania. In this study, job satisfaction, is accepted to be the multiplication of the actions of factors related to satisfaction from pay and benefits, peers, management and satisfaction from the superior.

\section{The Conceptual Model and Research Hypotheses}

The success at work of social services employees of penitentiary institutions is conditioned by several factors. Among these factors, with significant effects are considered to be those related to job environment, human relationship, salary, career, care in the development of their professional skills and others. The success of a social service employee is the result of action and interaction of these factors. In order to study these factors relationships and assess their effects we will use the following conceptual model: 


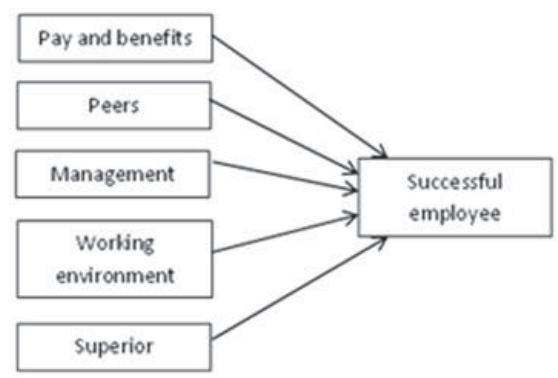

Figure 1. Conceptual model

The research hypothesis is formulated as follows:

$\mathrm{H}_{0}$ : The success of social workers depends on the level of satisfaction from pay and benefits, peers, management, working environment and their superior.

\section{Methodology}

\subsection{Tools}

The questionnaire is composed of questions about employee satisfaction and success. It was developed following the conceptual definition provided in literature survey (Matzler, et. al., 2007). The answers to each question are rated on a seven-point scale, from "very low" to "very high" (Table no.1). The opinion of their executive chief was taken for each of the employees interviewed. This opinion was also measured on a seven-point scale.

\subsection{The Sample}

36 social service workers who work in different Penitentiary Institutions and 25 chief executives were interviewed face to face.

\subsection{The Methods}

The data was analyzed with the following statistical methods:

The Confirmatory factor analysis (CFA) with varimax rotation was conducted to define the dimensions of job satisfaction. The regression analysis was performed using "Ordinary Least Squares Estimates" technique in order to measure effect of the latent variables defined by the CFA on success at work for Social Service Employees in penitentiary institutions.

\section{Results and Discussion}

The results of the confirmatory factorial analysis on the 25 employee satisfaction items are shown in Table no.1, 2. The Kaiser-Meyer-Olkin measure of sample adequacy is 0.812 . This supports the validity of CFA results. The 73.008 percent of the total variance is explained by the 5 first principal components (latent variables) with eigenvalues greater than 1 . The respective questions for each of the 5 latent variables are shown in Table no. 2 . Based on these questions the latent variables were named as: (i) satisfaction from pay and benefits, (ii) satisfaction from working environment, (iii) satisfaction from management, (iv) satisfaction from peers and (v) satisfaction from superior. The Cronbach's alpha values (Table no. 2) confirm the 5 latent variables reliability. 
Table 1. Factor analyze: Total Variance Explained

\begin{tabular}{|c|c|c|c|c|c|c|c|c|c|}
\hline \multirow{2}{*}{ Component } & \multicolumn{3}{|c|}{ Initial Eigenvalues } & \multicolumn{3}{c|}{ Extraction Sums of Squared Loadings } & \multicolumn{3}{c|}{ Rotation Sums of Squared Loadings } \\
\cline { 2 - 11 } & Total & $\%$ of Variance & Cumulative \% & Total & $\%$ of Variance & Cumulative \% & Total & $\%$ of Variance & Cumulative \% \\
\hline 1 & 5.024 & 28.062 & 28.062 & 5.024 & 28.062 & 28.062 & 3.508 & 26.704 & 26.704 \\
\hline 2 & 3.113 & 17.627 & 45.689 & 3.113 & 17.627 & 45.689 & 2.192 & 18.620 & 46.324 \\
\hline 3 & 1.932 & 11.939 & 57.628 & 1.932 & 11.939 & 57.628 & 2.807 & 10.804 & 57.128 \\
\hline 4 & 1.466 & 8.065 & 65.693 & 1.466 & 8.065 & 65.693 & 1.916 & 9.901 & 67.029 \\
\hline 5 & 1.193 & 7.315 & 73.008 & 1.193 & 7.315 & 73.008 & 1.566 & 5.979 & 73.008 \\
\hline 6 & .946 & 4.566 & 77.574 & & & & & & \\
\hline 7 & .784 & 3.611 & 81.185 & & & & & & \\
\hline 8 & .709 & 1.168 & 82.353 & & & & & & \\
\hline 9 & .697 & 1.103 & 83.456 & & & & & & \\
\hline$\ldots \ldots \ldots . . . \ldots . .$. & $\ldots \ldots .$. & $\ldots \ldots .$. & & & & & & \\
\hline 25 & .0001 & 0.0006 & 100.00 & & & & & & \\
\hline Extraction Method: Principal Component Analysis. & & & & & \\
\hline
\end{tabular}

Table 2. Rotated Component Matrix

\begin{tabular}{|c|c|c|c|c|c|}
\hline & \multicolumn{5}{|c|}{ Component } \\
\hline & 1 & 2 & 3 & 4 & 5 \\
\hline & Pay and benefits & Working environment & Management & Peers & Superior \\
\hline Adequate remuneration for work & .812 & & & & \\
\hline Satisfied provision salary increment & .729 & & & & \\
\hline Salary increases on performance & .701 & & & & \\
\hline satisfaction from non-financial rewards & 662 & & & & \\
\hline Job evaluated reward & .613 & & & & \\
\hline Available opportunities for promotion & & .745 & & & \\
\hline Satisfied with available opportunities & & .702 & & & \\
\hline Feel proud of job & & .689 & & & \\
\hline Training program regularly & & .657 & & & \\
\hline Use skill, experience and qualification & & .643 & & & \\
\hline Top management support & & .640 & & & \\
\hline Satisfied environment & & .608 & & & \\
\hline Recognition for good work & & & .761 & & \\
\hline Motivated to work & & & .704 & & \\
\hline Flexibility working hours & & & .689 & & \\
\hline \begin{tabular}{|l} 
Like job \\
\end{tabular} & & & .672 & & \\
\hline Job meaningful & & & .658 & & \\
\hline Relationship-colleagues & & & & .801 & \\
\hline Collective work & & & & .765 & \\
\hline Team work & & & & .655 & \\
\hline Colleagues help & & & & .604 & \\
\hline Supervisors care & & & & & .783 \\
\hline Trust between superior and subordinates & & & & & .757 \\
\hline Exchange of ideas between superior and subordinates & & & & & .703 \\
\hline Cronbach's Alpha & 0.83 & 0.79 & 0.72 & 0.69 & 0.68 \\
\hline
\end{tabular}

The results of the estimation of the linear dependency between the five latent variables consider as independent variables and depend variable: success of the work of the Social Service Workers, are presented in Table no.3, 4,5. 
Table 3. Model Summary

\begin{tabular}{|c|c|c|c|c|}
\hline Model & R & R Square & Adjusted R Square & Std. Error of the Estimate \\
\hline 1 & $.812^{\mathrm{a}}$ & .659 & .604 & 1.062 \\
\hline \multicolumn{4}{|l}{ a. Predictors: (Constant), PB, WE, Ma, Peer, Sup. } \\
\hline
\end{tabular}

Table 4. ANOVAa

\begin{tabular}{|c|c|c|c|c|c|}
\hline Model & Sum of Squares & $\mathrm{df}$ & Mean Square & $\mathrm{F}$ & Sig. \\
\hline Regression & 342.86 & 5 & 54.14 & 15.20 & $.00^{\mathrm{b}}$ \\
\hline 1 Residual & 107.52 & 30 & 3.58 & & \\
\hline Total & 450.38 & 35 & & & \\
\hline \multicolumn{6}{|c|}{ a. Dependent Variable: success of the work } \\
\hline \multicolumn{6}{|c|}{ b. Predictors: (Constant), PB, WE, Ma, Peer, Sup. } \\
\hline
\end{tabular}

Table 5. Coefficients ${ }^{\mathrm{a}}$

\begin{tabular}{|c|c|c|c|c|c|}
\hline \multirow{2}{*}{ Model } & \multicolumn{2}{|c|}{ Unstandardized Coefficients } & Standardized Coefficients & \multirow{2}{*}{$\mathrm{t}$} & \multirow{2}{*}{ Sig. } \\
\hline & $\bar{\beta}$ & Std. Error & $\beta$ & & \\
\hline (Constant) & 4.163 & .061 & & 46.671 & .000 \\
\hline PB & .498 & .060 & .461 & 7.465 & .001 \\
\hline WE & .102 & .059 & .136 & 4.190 & .050 \\
\hline $\mathrm{Ma}$ & 211 & .062 & 296 & 3.879 & .052 \\
\hline Peer & .329 & .059 & 381 & 4.011 & .050 \\
\hline Sup & .098 & .063 & .082 & 3.981 & .052 \\
\hline
\end{tabular}

The adjusted $\mathrm{R}^{2}$ is 0.604 which means that practically $60 \%$ of the dependent variable (success of the work) can be explained by the independent variables. The remaining $40 \%$ are the effects of other factors such as personal evaluations, psychological and sociological influences and subjective evaluations which are not part of this model.

Table no. 5 shows the standardized regression coefficient for all variables. Referring to t-test values all these coefficients are statistically significant $(p<0,05 ; p<0,01)$. Therefore, we can confirm that the hypothesis about the relationship between independent variables ( 5 latent variables) and dependent variable (success at work) are statistically significant.

Referring to the partial regression standardized coefficient we can confirm that the most important factor is pay and benefits, $\beta=0.461$ ( $p<0.01)$, followed by satisfaction from peers $\beta=0.381(p<0,05)$, management $\beta=0.296(p<0,05)$. On the other hand, working environment $\beta=0.136(p<0,05)$ and superiors $\beta=0.082(p<0,05)$ have comparatively less impact on success at work of the Social Service Employees.

Given that all the partial regression standardized coefficient have positive value, the managerial policies aiming at increasing success at work for social service employees, should focus on: (i) higher pay and financial or nonfinancial benefits, (ii) support of good colleague's relationship and team working and (iii) capacity building to support improvement of working environment, motivation of social workers and working hours flexibility.

The penitentiary administration should support the opportunities for promotion and for creating a satisfied environment. Training programs should be a priority. Implementation of the necessaries conditions for more effective use of skill, experiences and qualification of social workers, together with the efforts to create a reliable environment, to enhance care for dependents and to promote the exchange of ideas between superior and subordinates should be part of the list of priorities for the penitentiary administration.

\section{Conclusions}

This study aims to analyze employee satisfaction and the factors affecting the overall success of Social Service Employees of Penitentiary Institutions in Albania. 
The Factorial Analyze identified five factors as latent variables: satisfaction from pay and benefits, working environment, management, peers and superior; that have a positive relationship with the Social Service Employees success at work. The main important factors of this analysis were pay and benefits, followed by peers and management. In contrast, working environment and relation with superiors have less impact on their success at work.

\section{References}

Bernal, J.G., Castel A.G., Navarro, M.M., and Torres P.R., (2005), "Job satisfaction: empirical evidence of gender differences", Women in Management Review, vol. 20, No. 4.

Cranny, C.J., Smith, P.C., and Stone, E.F. (1992), Job satisfaction: How people feel about their jobs and how it affects their performance, Lexington Books, New York.

Homburg, Ch., Stock, R. (2004), The Link Between Salespeople's Job Satisfaction and Customer Satisfaction in a Business-to-Business Context: A Dyadic Analysis, Journal of the Academy of Marketing Science, 32, 2, 144-158.

Ilham Dahir Sheikh Mohamoud (2009). The role of work motivation on employee performance. Master's thesis. Universiti Utara Malaysia, Kedah.

Kume, E. 2013 "Punonjesi social ne sistemin e drejtesise dhe arsimin parauniversitar. Master" thesis. University of Tirana, Albania

Locke, E.A., (1969), "What is job satisfaction", Organizational Behavior and Human Performance, Vol. 4, Iss. 4, pp. 309-336.

Locke, E. A. (1976). The nature and causes of job satisfaction. In M. D. Dunnette (Ed.), Handbook of industrial and organizational psychology (pp. 1297-1349). Chicago: Rand McNally.

Lund, D.B. (2003), "Organizational culture and job satisfaction", Journal of Business and Industrial Marketing, Vol. 18, № 3, pp. 219-236.

Zaim, H., Zaim, S. 2013 Measuring employee satisfaction in small and medium sized enterprises.

First International Conference on Management and Economics, "Epoka" University, Tirana, Albania 
